\title{
UTILIZAÇÃO DAS CORES EM AMBIENTES RESIDENCIAIS
}

\author{
Mirian Nunes de Carvalho Nunes \\ Faculdade Pitágoras - MA \\ decarvalhomirian@gmail.com \\ Cláudia do Rosário Matos Nogueira \\ Universidade Federal do Maranhão - UFMA \\ claudiamanog@hotmail.com \\ Tyla Mendes Ricci \\ Faculdade Pitágoras - MA \\ tylaricci@hotmail.com
}

Resumo: A utilização das cores em ambientes residenciais. Aborda-se a percepção das cores pelos aspectos físicos e fisiológicos, sua classificação, simbologia e relação com a iluminação, bem como apresenta exemplos de esquemas cromáticos, fundamentação teórica e prática de alguns profissionais relativos à sua aplicação. Esta pesquisa tem como finalidade reunir informações básicas que subsidiem a sugestão para aplicação da cor em espaços residenciais. O objetivo é demonstrar sua influência, a importância de sua utilização, os exemplos de cores para ambientes por meio de pesquisas em fontes teóricas sobre o assunto e entrevista com profissional atuante em ambientações, revelando esquemas cromáticos e os efeitos psicológicos que elas podem causar, assim como ressaltar a teoria de alguns autores e a prática de profissionais da área de design de interiores. Este trabalho direciona-se a profissionais e estudantes de Desenho Industrial, Design de interiores e Arquitetura, possibilitando orientá-los na concepção de seus projetos de ambientação, dada a importância da correta aplicação da cor nestes locais.

Palavras-chave: Cores, Ambientações, Design de Interiores.

Abstract: The use of color in home environments. Deals with the perception of colors by physical and physiological aspects, its classification, symbolism and relationship with the lighting, and provides examples of color schemes, theoretical and practical of some professionals on its application. This research aims to gather basic information that support the suggestion for application of color in residential spaces. The goal is to demonstrate his influence, the importance of their use, examples of colors for environments through research on theoretical sources on the subject and interviews with professional working in ambiences, revealing color schemes and psychological effects they can cause, as well to underscore the theory of some authors and the practice of interior design professionals. This work 
directs to professionals and students of Industrial Design, Interior Design and Architecture, allowing guide them in designing their ambiance projects, because of the importance of correct application of color in these locations.

Keywords: Color, residential environments, Interior Design.

\section{INTRODUÇÃO}

Observa-se o uso de luz e cores produzidas artificialmente nos diversos ambientes que o homem frequenta, sejam ao ar livre, nas praças, shoppings, escritórios, consultórios, no ambiente de trabalho, ou mesmo em suas residências. Todos esses locais necessitam de um adequado planejamento da iluminação e aplicação das cores, principalmente naqueles que permanecem mais tempo. São fatores que contribuem para o bem estar coletivo e individual e aumentam o nível de satisfação das pessoas.

Por meio dos estímulos e efeitos psicológicos que as cores provocam no ser humano, podem curar problemas de saúde quando bem aplicadas, entretanto resultam em sensações negativas quando mal utilizadas. Dessa forma, as cores que podem ser utilizadas de maneira especial, aquecendo ambientes frios, refrescando locais ensolarados, criando atmosferas de alegria, higiene e, sendo insubstituíveis como elementos de combate a fadiga visual, que é a primeira etapa para o cansaço físico.

O objetivo desta pesquisa é demonstrar a influência das cores, a importância de sua utilização, os exemplos de cores para ambientes por meio de esquemas cromáticos e pelos efeitos psicológicos que elas podem causar, assim como ressaltar a teoria de alguns autores e a prática de profissionais da área de design de interiores.

Este trabalho direciona-se a profissionais e estudantes de Desenho Industrial, Arquitetura e áreas afins, possibilitando orientá-los na concepção de seus projetos de ambientação, dada a importância da aplicação da cor nestes locais.

\section{LUZ E COR}

A luz é a sensação que as ondas eletromagnéticas produzem sobre o olho humano. Trata-se de campos eletromagnéticos alternados que transportam energia através do espaço, que se difundem em forma de oscilações ou vibrações. (RE, 1978).

A interação entre a luz e a cor podem criar ambientes que traduzam sensações de aconchego, alegria, etc., mas o contrário pode prejudicar.

Objetivando melhor compreensão do estudo de aplicação da cor nos ambientes residenciais, é necessário abordar alguns conceitos e aspectos da luz, sua influência sobre as cores e vice-versa.

\subsection{Luz natural e artificial}

Conforme Re (1978) é por meio da luz natural e da luz artificial que obtemos $80 \%$ da impressão sensorial, logo sensação e percepção cromática, resultam da influência da luz sobre a cor e vice-versa. À unidade de luz ou fluxo luminoso, que é a 
quantidade de luz emitida por uma fonte luminosa na unidade de tempo, chama-se lúmen. O lux corresponde ao fluxo de um lúmen por metro quadrado.

Pilotto (1980) ressalta que a fonte de luz natural mais perfeita que se tem conhecimento é o sol, que emite luz em toda região visível do espectro e proporciona quantidades de lux (densidade de fluxo luminoso sobre uma superfície) variadas conforme o local em que incidem; em sol a pino no verão atinge 100.000 lux numa superfície horizontal ao ar livre; em dia nublado, céu com nuvens, atinge cerca de 10.000 lux; à sombra de uma árvore, em dia de sol, mede 10.000 lux e à sombra, sob uma cobertura, aproximadamente 5.000 lux.

Com a luz natural, o cansaço visual é menor, a cor tem seu valor exato e há economia de energia em relação à artificial. Mas há desvantagens devido a grande variação de fluxo luminoso que incide em uma área, chegando a alcançar de 100 a 200\% desse fluxo em questão de minutos (Ibid.).

A lâmpada é a principal fonte de luz artificial do mundo moderno, surgiu em 1878 através de Thomas Edison (1847 - 1931). O primeiro protótipo foi de uma incandescente, que resultou do aquecimento de um filamento pelo qual passava uma corrente elétrica. Diversos tipos surgiram a partir de então, como as fluorescentes, cujo funcionamento deve-se ao princípio de descarga elétrica através de um gás, produzindo luz. Recentemente as lâmpadas de led vêm ganhando espaços pela economia de energia apesar de não serem usadas totalmente para iluminação de interiores servem como pontos de iluminação para pequenos espaços.

Com a iluminação artificial é possível controlar a qualidade da iluminação e a quantidade de luz, que são fundamentais para a aplicação em ambientes.

A utilização das lâmpadas nos interiores residenciais deve ser planejada para proporcionar um ambiente agradável e acolhedor, atendendo a necessidade de cada local, bem como garantindo satisfação visual, lembrando que o uso em excesso, acarreta custos de energia elétrica, e a má distribuição gera problemas de ordem física e psíquica.

Existem vários tipos de lâmpadas disponíveis no mercado sendo quase impossível identificar todos. As lâmpadas incandescentes já foram as mais utilizadas nas residências, devido seu baixo custo na aquisição, mas ao mesmo tempo têm a desvantagem de ser pouco durável, cerca de 1000 horas de uso; tem alta produção de calor.

Também consideradas incandescentes, as halógenas possuem uma diferença, elas contêm pequenas quantidades de um gás halógeno (em geral, iodo), porém tem o mesmo princípio de funcionamento das incandescentes. São utilizadas na iluminação de destaque e decorativa, duram cerca de 2000 a 4000 horas.

As fluorescentes são também chamadas de lâmpadas de descarga. Evoluíram ao longo dos anos em relação à redução do diâmetro, possibilitando melhor eficiência das luminárias. Possuem vida útil em torno de 10.000 horas e o consumo de energia é $80 \%$ menor que as incandescentes.

Atualmente temos as de led que é um Diodo Emissor de Luz ("Light Emitting Diode", em inglês) um componente eletrônico que tem a capacidade de produzir luz através da eletroluminescência, fenômeno em que fótons são liberados depois que uma corrente elétrica passa por um campo que excita e separa os elétrons.

Com mais vantagens que as incandescentes inventadas por Thomas Edison há mais de um século tem muita eficiência: menos de $10 \%$ da energia consumida por uma 
lâmpada comum é usada para produzir luz, o restante é desperdiçado em forma de calor. Já nos LEDs, essa eficiência ultrapassa os 80\%. (MACHADO, 2011)

Além disso, LEDs podem ser fabricados em tamanhos muito menores, e são mais confiáveis: a maioria dos primeiros LEDs fabricados nos anos 80 e 90 estão em uso até hoje. Ainda assim, esses componentes são utilizados mais como indicadores luminosos do que como fontes de iluminação para locais com pouca luz, mas isso está mudando rapidamente.

\subsection{Relação entre cor e luz}

Existe uma correspondência entre a cor real de um objeto ou superfície e sua percepção de acordo com a fonte de luz incidente, a qual refere-se a sigla IRC (Índice de Reprodução de Cor). Lâmpadas que apresentam IRC igual a 100 reproduzem as cores com mais fidelidade. A reprodução das cores é diretamente proporcional ao IRC, ou seja, uma lâmpada com índice mais baixo reproduzirá menor fidelidade de cores. Para residências o IRC recomendado é entre 80 e 100.

Além do IRC, é necessário analisar o rendimento luminoso de um ambiente, pois o mesmo está relacionado às cores utilizadas no local. A cor branca não reflete mais que $80 \%$ da luz incidente e as cores escuras refletem menos que $10 \%$. Desta forma, recomenda-se empregar tons claros nas superfícies maiores para obter maior reflexão da luz incidente, quando necessário.

Deve-se observar a relação cor do ambiente $x$ iluminação, a fim de evitar ofuscamento, causado pela presença de luzes, janelas ou áreas excessivamente brilhantes, que se sobressaem mais no local, causando uma redução da eficiência visual.

\subsection{Esquema de cores}

Trabalhar cores não é tarefa das mais fáceis devido a subjetividade. Pilotto (1980, p.103) "recomenda a combinação de cores que tem por objetivo adequá-las harmoniosamente, evitando assim, as rivalidades entre si e os efeitos indesejáveis".

Para Vianna (1980) os esquemas de cores são representações das relações das cores escolhidas para um ambiente. Outro ponto de partida dependerá de um elemento decorativo componente do ambiente, podendo ser um tecido, papel parede etc. Conhecimentos sobre os esquemas de cores são importantes para aplicá-los em ambientes. Porém, vale ressaltar que na prática, a preferência do cliente e o aspecto psicológico das cores são fundamentais e extremamente considerados para que 0 espaço não venha contrastar com a personalidade de quem o habita.

Poore (1994) diz que os esquemas complementares são baseados na harmonia existente entre cores opostas do círculo das cores, por exemplo: verde e vermelho. São frequentemente notáveis e difíceis de executar, podendo por vezes tornar o ambiente carregado. Para evitar esse problema, uma das cores deve dominar e a outra servir de contraste.

Segundo Pilotto (1980, p. 104) nos esquemas análogos consideram-se três variações semelhantes de uma cor, por exemplo: amarelo-ouro, laranja, vermelhoalaranjado, onde o laranja entra na formação das duas outras que the são adjacentes; ou seja, são três cores, localizadas, uma ao lado da outra no círculo das cores. A estética geral e o efeito psicológico de esquemas análogos (ver Figura 1) dependem das cores específicas selecionadas. 
Conforme Vianna (1980) esquema monocromático, como dizem os franceses é "Ton sur ton", são variações de um mesmo tom, baseado nas tinturas, tonalidades e matizes de uma mesma cor, provocando uma sensação de continuidade (ver Figura 2). Para Poore, este tipo de esquema pode ser muito monótono, devendo, portanto, ser bem elaborado, evitando o domínio de um tom forte em grandes áreas.

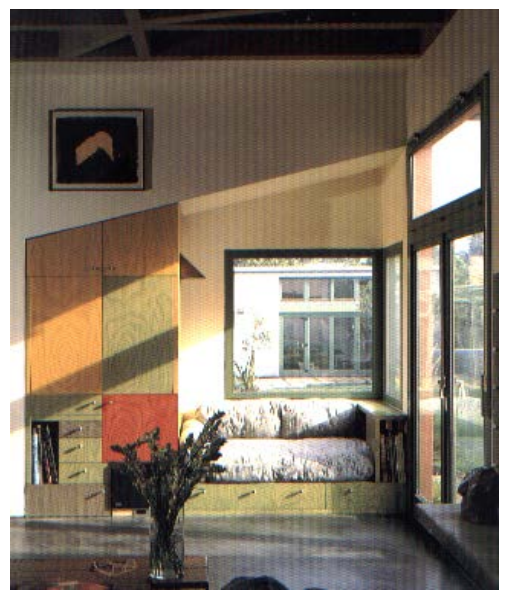

Figura 1 - Esquema análogo (laranja, verde e amarelo)

Fonte: Adaptado de POORE. Interior color by design.1994.

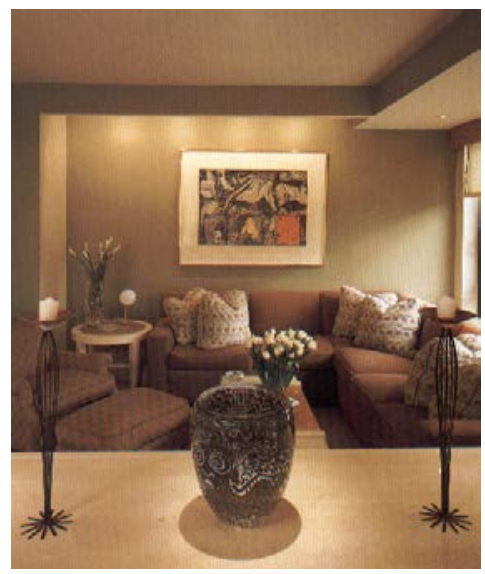

Figura 2 - Esquema monocromático (bege)

Fonte: Adaptado de AVES. El color em el interiorismo. 1994.

A combinação tripla ou tríade refere-se a três cores equidistantes no círculo das cores (ver Figura 3). Além dos ambientes residências, geralmente pode-se encontrar este tipo de combinação em sala de aulas para crianças na idade préescolar, em creches, clinicas pediátricas etc. $\mathrm{O}$ uso dessas cores dá-se por serem tons fortes que despertam a atenção das crianças.
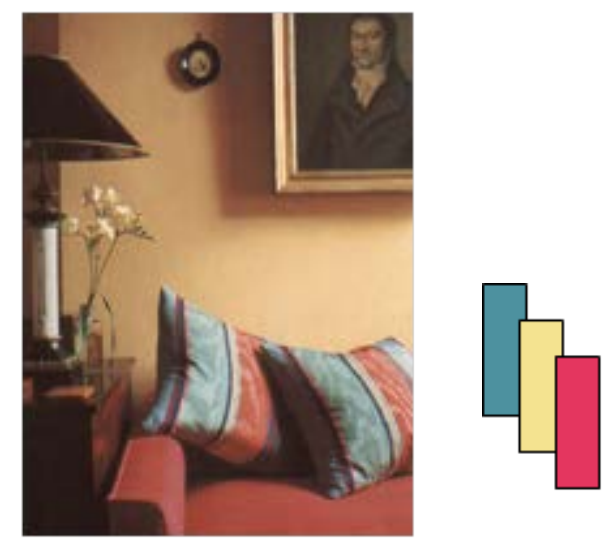

Figura 3 - Tríade (azul, amarelo e vermelho) Fonte: Adaptado de AVES. El color em el interiorismo. 1994.

\subsection{Simbologia das cores}


Durante muito tempo, foram atribuídos alguns significados às cores pelas sociedades de todas as épocas, relacionando-os ao desenvolvimento social e cultural. Isto fez com que estudos psicológicos a respeito do assunto fossem comparados com as relações entre os estímulos e os componentes fisiológicos, bem como sua influência no comportamento consciente e inconsciente em relação ao caráter moral e emocional.

As cores têm uma vasta aplicação nos dias de hoje e são facilmente reproduzidas por vários processos. Anterior ao século XIX, isto só era possível com uso de corantes de origem orgânica, que eram adquiridos somente por pessoas com recursos financeiros elevados.

Farina (1990) considera a criação diversificada e colorida de vários objetos e materiais que temos hoje só foi viável devido aos processos de elaboração utilizados como a síntese dos corantes de anilina, os derivados de alcatrão e hulha e os óxidos metálicos. Estes foram os passos iniciais para o surgimento de variação das cores.

Pilotto (1980) ressalta que fatores como o sexo, a idade, o nível social e cultural das pessoas, podem exercer uma influência na reação das mesmas em relação às cores, porém, sabe-se que alguns efeitos são genéricos, podendo as cores atrair ou repelir, provocar agressividade ou passividade, tensão ou calma, sensação de frio ou de calor, de acordo com a associação feita a cada cor.

Elas ainda têm o poder de curar paralelamente de acordo com suas vibrações magnéticas, emotivas, com características próprias que podem ser usadas conforme suas influências. Atualmente, desempenham papel importante nos centros de tratamento de enfermidades, utilizando a técnica da cromoterapia para auxiliar na cura através das cores.

Cada cor traz consigo uma longa história e significados psicológicos partindo de experiências e pesquisas de cientistas. Estes significados não tratam de questões fixas ou definidas, mas podem transformar ou conduzir os processos que envolvem as cores e os indivíduos, porém é uma referência que contribui para o uso mais apropriado das mesmas.

Segundo Farina (1990) expõem-se alguns significados que os cientistas estabeleceram a respeito da interpretação psicológica das cores acromáticas e das cromáticas básicas como referência. O branco resulta da mistura de todos os matizes do espectro solar, é síntese aditiva das luzes coloridas. Em pigmento, branca é a superfície que reflete os raios luminosos contidos na luz branca. Origem da palavra: germânica - blank. Significado: brilhante. Simboliza a luz. Para os orientais significa o medo, a morte, o fim, o nada e para os ocidentais significa a vida, o bem. Associa-se a simplicidade, limpeza, juventude, otimismo, paz, pureza, infância, harmonia, estabilidade, etc.

Um corpo é denominado de preto por absorver quase todos os raios luminosos que incidem sobre ele, refletindo o mínimo desses raios. Tem maior destaque em oposição ao branco. "Origem da palavra: latim - niger. Significado: escuro, preto, negro". Quando combinado com certas cores, torna-se alegre; Associase com noite e a maioria das vezes com aspectos negativos como melancolia e opressão. Geralmente na decoração o preto é aplicado como elemento de contraste, ressaltando a qualidade relacionada à luminosidade e vibração dos matizes. (Ibid, p.113). 
Vermelha é cor fundamental ou primitiva por ser uma das sete do espectro solar. Possui maior comprimento de onda, tem elevado grau de cromaticidade, por isso possui maior visibilidade em relação às demais, é rapidamente distinguida pelos olhos. Origem da palavra: latim - vermiculus. Associa-se com rubi, sinal de parada, perigo, vida, sol, chama, sangue, dinamismo, força, energia, paixão, calor, emoção, ação, agressividade, alegria comunicativa, extroversão. (Ibid.).

Amarelo é uma das três cores primitivas. É a mais clara das cores e na escala de tons chega próximo ao branco. "Cor quente por excelência na distinção psicológica. Origem da palavra: latim - amaryllis". Simboliza a cor da luz irradiante em todas as direções. Associa-se a luz, verão, calor de luz solar, iluminação, conforto, alerta, adolescência, espontaneidade, euforia. (Ibid, p.114).

O azul, das três cores primárias é a mais escura e a mais profunda, onde o olhar penetra e se perde no infinito. Considerada, também imaterial, presente na superfície transparente dos corpos. Origem da palavra: árabe - lázúrde e persa lazaward. Associa-se com frio, mar, céu, gelo, feminilidade, afeto, a intelectualidade, a paz, a distância, a serenidade, o infinito, a meditação. (Ibid.).

Devido as cores que the dão origem, o laranja é uma cor quente. Parece aproximar-se do observador quando comparada com cores frias. Origem da palavra: persa - narang e do árabe - naranja. Associa-se com outono, laranja, fogo, pôr do sol, luz, chama, calor, raios solares, energia, alegria, prazer. (Ibid.).

Verde é ponto ideal de equilíbrio entre a mistura do amarelo e azul. É cor reservada e de paz repousante, favorece o desencadeamento de paixões. Origem da palavra: latim - viridis. Associa-se com frescor, umidade, águas claras, mar, verão, natureza, adolescência, bem-estar, paz, saúde, tranquilidade. (Ibid.).

Violeta ou violáceas, também chamada de roxo, designa genericamente todas as cores que resultam da mistura do vermelho com azul. "Origem da palavra: latim russeus. Associa-se com a noite, igreja, sonho, mar profundo, fantasia, mistério, justiça, misticismo, espiritualidade, delicadeza." (Ibid., p.115).

Púrpura, obtida da mistura de $2 / 3$ de vermelho e $1 / 3$ de azul, possuindo ponto de equilíbrio definido. Origem da palavra: latim - purpura. Associa-se com vidência, abundância, riqueza, autoridade, poder. (Ibid).

A análise dos significados atribuída às cores facilita sua aplicação pelos profissionais da área de ambientação assim como a interpretação (conforme informações adquiridas em conversas) da personalidade das pessoas e de suas preferências, contribuindo também para a escolha da composição adequada destinada aos ambientes de modo geral.

\section{CORES NOS AMBIENTES RESIDENCIAIS}

A busca pela qualidade de vida, pelo conforto, bem-estar e satisfação pessoal ressalta a importância da aplicação das cores nos ambientes residenciais. Desta forma a função do ambiente, a personalidade do usuário e os efeitos psicológicos desejados estão diretamente relacionados à sua utilização. Deve-se analisar cada caso uma vez que não há regras pré-definidas.

A sala de estar é o compartimento onde normalmente se recebem as visitas, se conversa, ouve música, assiste TV e relaxa. Em pequenas residências serve também como jantar social, sendo um ambiente destinado ao lazer, descanso e 
entretenimento, onde as pessoas permanecem por longo período de tempo, por isso deve receber uma atenção toda especial quanto à ventilação, iluminação e cores, para que se torne agradável e aconchegante.

O quarto, de modo geral, destina-se particularmente ao repouso e sono, e tem quase sempre como função acessória servir de vestiário, o que pede um ambiente acolhedor e relaxante, em que as cores mais indicadas devem ser balanceadas com a personalidade do cliente, devendo atender às suas necessidades.

A cozinha é a parte da casa onde se preparam os alimentos, lavam-se louças e utensílios. Por vezes é o local onde são feitas as refeições rápidas como lanche ou café da manhã. Este ambiente deve ser agradável, prático, funcional e ter aspecto de limpeza.

O banheiro destina-se ao asseio corporal e às necessidades fisiológicas, este ambiente deve ser relaxante, prático, limpo e funcional e o hall permite a circulação entre os diversos cômodos, é uma área de função acessória, servindo praticamente só para passagem, por isso é designado como área de permanência transitória e não é interessante que tenha grandes dimensões.

Salomão (2000) explica que não há regras para aplicação das cores, mas devese considerar o valor atribuído à personalidade do cliente, o que inclui gosto, comportamento, jeito de ser etc. A personalidade determina que o pensamento e o comportamento característicos de uma pessoa e sua adaptação típica ao meio social, dependem de sistemas psicofísicos, em virtude da qual o homem age de determinada maneira e não de outra, tal como se inferiu do seu comportamento. É o estilo de vida do indivíduo, ou a maneira característica de reagir aos problemas da vida, incluindo as metas vitais.

Dentro dos tipos de personalidade cita-se a de Carl G. Jung que as classifica em tipo introvertido e extrovertido. O introvertido correspondendo ao indivíduo que não atribui ao objeto externo a importância que a maioria lhe confere, com tendência a concentrar-se nos próprios pensamentos e ensimesmar-se (autismo); o extrovertido corresponde àquele indivíduo que vive de acordo com a necessidade externa e é orientado para as relações objetivas e se interessa pelas coisas exteriores ao eu, especialmente em seu ambiente imediato.

Conforme Poore (1994), o ambiente geralmente é composto de muitos elementos inter-relacionados, incluindo espaço, forma, estrutura, luz, textura e cor. Porém destes, a cor, é algumas vezes relegada a segundo plano quando não há orientação de um profissional, fato que não deveria acontecer, uma vez que ela é parte integrante da ambientação e, para seu uso efetivo, basta uma simples questão de planejamento.

O caráter objetivo e subjetivo da cor é importante para entendermos sua utilização, sem o primeiro não a conheceríamos e sem o segundo não teríamos fundamentos para aplicá-las, nem mesmo para quem mostrá-las, isso explica a complexidade de sua aplicação que se encontra voltada para a valorização desses objetivos, que tem base fundamental no conhecimento teórico e prático da composição cromática. (SALOMÃO, 2000).

A escolha da cor na ambientação deve ser submetida à orientação de profissional especializado na área, sempre levando em conta o gosto individual de cada cliente para não ocorrer conflitos com a sua personalidade, pois segundo Siqueira (1991) é um erro pensar que pessoas extrovertidas devem conviver com cores frias 
com o intuito de acalmá-las, e que aquelas introvertidas, necessitem conviver com cores quentes para animá-las.

De acordo com profissionais da área, há casos em que se faz necessário o uso de cores determinadas para tratar problemas de saúde. Por exemplo: pessoas altamente depressivas que fazem tratamento pela técnica da cromoterapia necessitam, por vezes, de uma cor quente no ambiente de dormir para equilibrar suas emoções.

Para aplicação das cores, deve-se levar em conta que estas não são utilizadas apenas em paredes, mas integram outros componentes da ambientação entre eles: colchas, cortinas, estofados, almofadas e adornos.

\subsection{Efeito e recomendações das cores nos ambiente residenciais}

Dependendo de como é utilizada no ambiente, a cor pode variar a percepção do local. A melhor forma de vê-la consiste em observar todos os elementos formadores do mesmo como uma unidade de cores. Sendo assim, a cor, de todos os elementos é importante para uma boa composição. Sua utilização em ambientes pode mostrar bons resultados quando é bem estudada e aplicada, considerando alguns pontos como:

$\forall$ Fixar o tom emocional. É quando o ambiente transmite sensações de emoção, alegria, nostalgia, serenidade etc., por meio das cores (ver Figura 4);

$\forall$ Enfocar ou desviar atenção. A cor poderá definir um ponto de atração no ambiente, ressaltando algum móvel, adorno ou obra de arte, sendo destaque neste interior, o que se pode denominar de ponto focal (ver Figura 5);

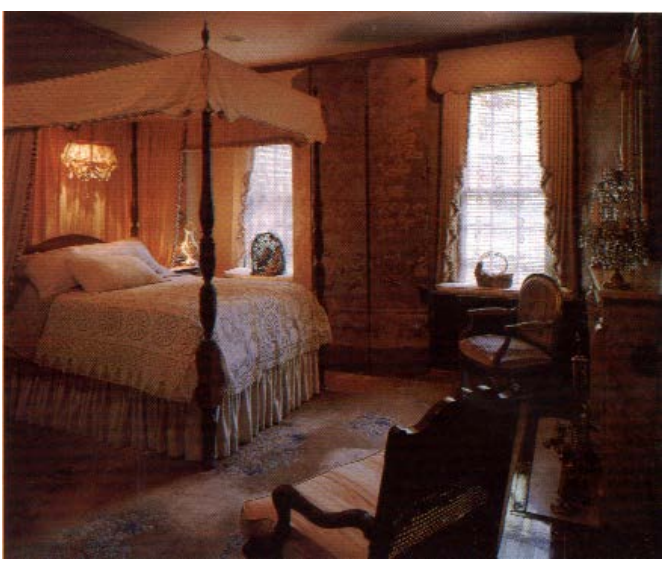

Figura 4 - A cor como fixação do tom emocional Fonte: Adaptado de AVES. El color em el interiorismo. 1994.

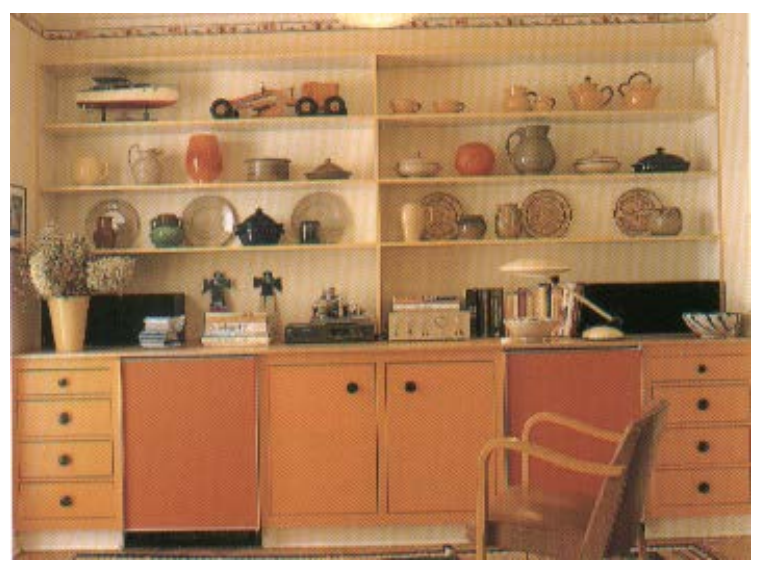

Figura 5 - A cor como enfoque da atenção Fonte: Adaptado de POORE. Interior color by design. 1994.

$\forall$ Modular o espaço para percebê-lo maior ou menor. A cor definida para predominar no local, deverá transmitir a sensação de uniformidade, unindo elementos do ambiente, o que pode dar a impressão de ser maior ou menor (ver Figura 6);

$\forall$ Separar, definir e unificar espaços (ver Figura 7). 


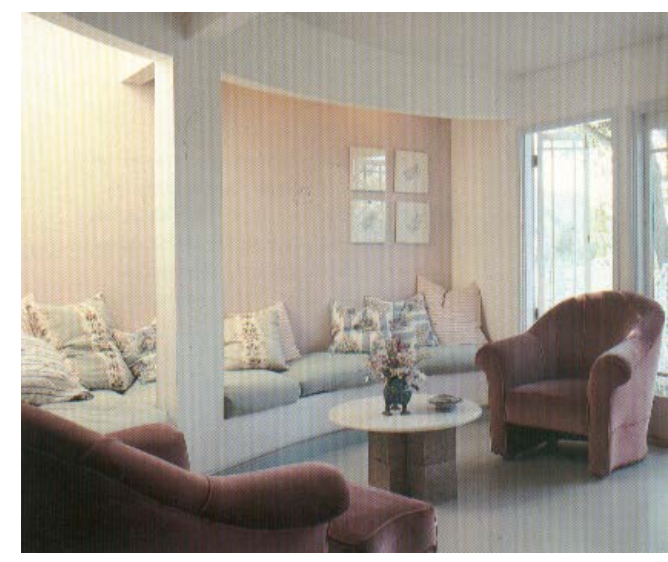

Figura 6 - A cor na modulação do espaço Fonte: Adaptado de POORE. Interior color by design. 1994

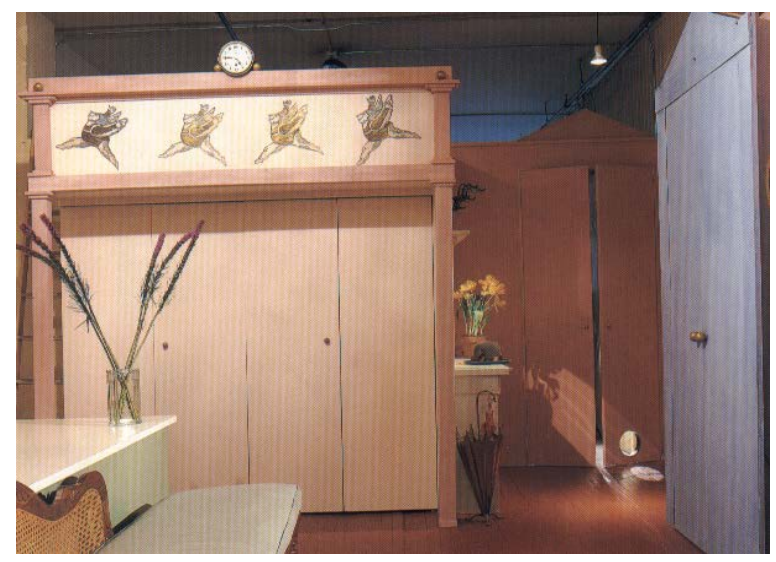

Figura 7 - A cor na unificação do espaço Fonte: Adaptado de POORE. Interior color by design. 1994

Aplicando-se as cores de forma geral, eis alguns efeitos que podem ser conseguidos: tom claro em espaços pequenos faz com que estes pareçam maiores do que são realmente. Vidros e espelhos refletem luz, clareando e dando a sensação de que os ambientes são maiores. Pintando de cor escura a parede do fundo de uma sala muito longa, ela parecerá mais curta. Para quebrar a simetria de ambientes quadrados, uma boa opção é usar uma parede colorida.

Segundo Siqueira (1991), o branco aplicado nos ambientes, admite o mínimo de erro, mas seus efeitos podem ser estressantes e causar impaciência e irritação, por não ser estimulante. A exposição prolongada a essa claridade força a vista, podendo "causar danos aos olhos ou agravar problemas existentes". Um melhor efeito é obtido dependendo da composição do ambiente como um todo, dos contrastes criados entre figura e fundo através da utilização de peças decorativas ou adornos.

Uma boa opção para tetos altos é empregar uma cor escura no forro para fazê-lo parecer mais baixo. Para que tetos baixos pareçam mais altos, usam-se tons claros. Aves (1994) sugere cores metálicas para realçar detalhes arquitetônicos, criando um efeito ligeiramente brilhante; acabamentos envernizados para conseguir profundidade e atenção; uma cor no teto parecida com a da parede, porém mais clara, dá a sensação do ambiente ser maior.

Recomenda-se trabalhar as maiores amostras de cores, testando-as sempre que possível em uma área de aproximadamente $1 \mathrm{~m} \times 1 \mathrm{~m}$ no espaço a ser usado, seja parede, teto ou piso. É ideal que a amostra seja observada no local onde será aplicada, pois cada superfície recebe uma quantia e qualidade de luz diferente. As amostras devem ser vistas com a luz do dia e também em qualquer fonte de luz artificial.

Para definir a cor do ambiente opta-se também por esquemas criados conforme a necessidade do projeto que, por vezes, essa característica, reflete o estilo do profissional e se converte numa tendência. O hall de entrada, por exemplo, é local de passagem, portanto é o primeiro ambiente de uma residência. Lacy (1996) sugere, por exemplo, amarelo para pessoas de ideias e vasto campo de interesses.

Sala de estar e jantar, por vezes estão aliadas e devem ser aconchegantes, pois são os locais onde algumas famílias se reúnem e recebem os amigos. Desse modo, conforme Lacy (1996), pretendendo-se usufruir de uma conversa estimulante, o amarelo forte ou uma das tonalidades do laranja são indicadas como principais, pois, estimulam o convívio e a sociabilidade. 
Com azul, a conversa geralmente tenderá a assuntos mais sérios. Quando as cores vermelhas são usadas, proporcionam uma sensação de intimidade. As cores sugeridas devem ser auxiliadas sempre com uma cor complementar ou tons realçantes, criando um efeito agradável. (Ibid.).

O violeta parece ser uma cor de contrastes, em tons claros transmitem romantismo, delicadeza e fragilidade, em tons escuros denotam força e poder, é a cor da realeza. Neste tom o ambiente transmite sofisticação para um oportuno refugio. 0 laranja é indiscutivelmente versátil, capaz de transmitir grande energia em cor pura e, em tons de terra, evocam conforto e segurança. (Ibid.)

Para Lacy (1996) a cozinha, é o lugar em que a comida é preparada, é um dos ambientes mais importantes da casa. Atualmente, é o centro da casa; a família se reúne nela para comer, conversar e relaxar, precisa ser um ambiente que propicie a descontração e o convívio. $O$ amarelo influencia nas refeições, estimulando a comer mais depressa e a falar muito, o que não ajuda na digestão.

Não se recomenda os tons de azuis na cozinha, pois inibem o apetite. 0 vermelho é indicado com moderação, pois ativa sentimentos negativos, é uma cor extremamente emocional e excita rapidamente. Embora o azul não seja recomendado, não quer dizer que é impedido de ser usado. Aves (1994) associa esta cor com água, limpeza e ordem, fatores relevantes na cozinha.

Para o quarto recomendam-se cores frias e relaxantes para se descansar antes de dormir. Dessa forma Lacy (1996) sugere as tonalidades de azul, que liberam o peso das atividades do dia, por ser uma cor mais fria dá a sensação de 'esfriar' rapidamente a atividade nas células do cérebro". Evitar os tons de amarelo como cor principal, mesmo um tom pálido de amarelo estimula muito a mente. Um tom claro de verde maçã combina bem com uma cor quente. O vermelho não é recomendado para os quartos segundo Aves (1994), devido a sensação de energia estimulante que a cor possui.

Sugere-se predominantemente para o banheiro o branco ou cores neutras, as outras cores servem de detalhes e acessórios. Como geralmente não possuem grandes dimensões, o branco passará a sensação de amplitude ao local e não será monótono aliado com outra cor.

Pode-se perceber que a aplicação da cor implica em fatores já citados, que devem ser observados e analisados, com indicação correta para cada local. O sentido psicológico pode também interferir nas diferentes culturas, as referências feitas ao uso da cor são sugestões, não sendo leis, é importante observar-se também os aspectos climáticos e culturais das regiões.

\section{CONCLUSÃO}

A aplicação das cores nos ambientes é uma tarefa complexa em que se deve verificar, o homem e o seu meio como um todo, na busca de uma harmonia e composição equilibrada que se traduz pela interação das cores e seus tons. Não dispondo de regras fixas para obtenção desse objetivo, conta-se com a subjetividade aliada ao talento e percepção do profissional, como pontos importantes para introduzir as cores nos ambientes.

O caráter subjetivo relativo ao aspecto psicológico, esta ligado às sensações e estímulos que as cores podem transmitir aos indivíduos, como podem reagir em 
relação a elas e suas preferências ou desagrados; o aspecto filosófico refere-se à cultura, meio social e à questão estética, interferindo na relação entre os seres, pois, o que pode ser bonito ou agradável a um, pode ser feio e desagradável a outros. É necessário, portanto, o conhecimento teórico e prático da composição cromática como base fundamental nesse estudo.

A aplicação da cor não é imutável e não se utiliza de forma generalizada, cabendo ao profissional da área estudar os casos minuciosamente, definir composições que se afinem com o usuário do ambiente e interferir no meio buscando a identidade entre o ser e seu habitat.

A aplicação das cores não é assunto tão simples, não só no segmento de ambientação de interiores, mas também em outros ramos, devendo-se utilizá-las considerando seu propósito e os efeitos fisiológicos e psicológicos. O entendimento pode melhorar não só o meio, mas o convívio e o bem estar dos indivíduos, proporcionando maior harmonia entre cor e forma, eliminando o aspecto frio e pesado das edificações e transformando os ambientes, tornando-os alegres, acolhedores e agradáveis para as pessoas que ali vivem ou circulam.

\section{REFERÊNCIAS}

AVES, John, AVES, Melanie. El Color en el Interiorismo. Massachusetts: Rockport, 1994.

FARINA, Modesto. Psicodinâmica das cores em comunicação. São Paulo: Edgard Blücher Ltda, 1990.

GOLDMAN, Simão. Psicodinâmica das cores. 4. ed. Brasília: DESED Editora , 1964. IIDA, Itiro. Ergonomia. Projeto e Produção. São Paulo: Edgard Blücher Ltda. 1992. LACY, Marie Louise. O poder das cores no equilíbrio dos ambientes. São Paulo: Pensamento, 1996.

MACHADO, Jonathan D. Conheça cinco tecnologias LED que vão dominar o mundo. 18 set 2011. Disponível na internet por http em:

http://tecnologia.terra.com.br/eletronicos/conheca-cinco-tecnologias-led-que-vaodominar-o-mundo,80c8fbd1680ea310VgnCLD200000bbcceb0aRCRD.html. Acesso em 28 mai. 2016

PEDROSA, Israel. Da cor a cor inexistente. Rio de Janeiro: Léo Christiano Editorial Ltda, 1989.

PILOTTO NETO, EGYDIO. Cor e iluminação nos ambientes de trabalho. São Paulo: Livraria Ciência e Tecnologia Editorial Ltda, 1980.

POORE, Jonathan. Interior color by design: a design tool for architects, interior designers, and homeowners. Massachusetts: Rockport, 1994.

RE, Vittorio. Iluminação interna civil e industrial. São Paulo: Hemus, 1978.

SALOMÃO, Andreia. Designer. Entrevista sobre o uso das cores em ambientes residenciais. São Luís, 2000.

SIQUEIRA, Suzana, O misterioso poder das cores. Nova. São Paulo, v.19, n.9, p.124127, set. 1991. 
THE COLOR BOOK. San Francisco: Chronicle Books, 1977.

VIANNA. Zeila Ribas. Curso de decoração programado. Curitiba: Bolsa Nacional do Livro, 1980. 4v. 